\title{
Patent Foramen Ovale and Cryptogenic Strokes: Is Device Closure Necessary?
}

\section{Kar SK*}

Department of Cardiac Anaesthesiology, Institute of Postgraduate Medical Education \& Research, Kolkata, India

*Corresponding author: Sandeep Kumar Kar, Department of Cardiac Anesthesiology, Institute of Postgraduate Medical Education \& Research, Kolkata, India

Received: March 19, 2017; Accepted: March 27, 2017; Published: March 31, 2017

\section{Prespective}

Dr. Julius Cohnheim first attributed Patent Foramen Ovale (PFO) with the occurrence of cryptogenic strokes [1]. The type of PFO, the degree and direction of flow and tunnel type anatomy of PFO have been attributed with the increased occurrence of strokes.

Approximately at the $5^{\text {th }}$ week of development, a very thin septum primum begins to grow downwards towards the endocardial cushion. The hiatus in between both structures forms the foramen primum. As the growth of the septum primum continues, apoptotic changes within the septum originate the foramen secundum. On the right atrial surface of the foramen secundum, a more muscular and thicker septum secundum migrates downwards covering the foramen secundum and leaving a small foramen on the bottom of the atrium, thissma; 1 foramen is called foramen ovale. In multiple autopsy reports, the prevalence of PFO in the adult population is approximately $26 \%$ [2]. The prevalence of PFO is similar by noninvasive methods with TEE [3]. However, the incidence of PFO in young patients presenting with cryptogenic stroke can reach up to $50 \%[4]$

The presence of a prominent Eustachian valve (EV) has been proposed as responsible for re-directing blood flow towards the septum, potentially allowing emboli to travel through the inter-atrial septum into the left atrium. This hypothesis was evaluated with TEE by Schuchlenz et al. by comparing patients who had cryptogenic strokes to healthy volunteers and found a significantly higher incidence of PFO and EV in those patients with cryptogenic stroke [5].

Stone et al. In a prospective follow up of stroke patients found to have a PFO during TEE and divided them into "large" degree shunting ( $\geq 20$ micro bubbles) and "small" degree shunting ( $\geq 3$ but $<20$ micro bubbles). Patients with "large" shunts had a $31 \%$ incidence of a recurrent event versus none in the "small" shunt group despite the use of antiplatelet and/or anticoagulation. Therefore, patients with "large" shunts should be considered at a significantly higher risk for subsequent adverse neurologic events [6]. It has also been proposed that "long-tunnel" PFO anatomy represents a favourable environment for clot formation, with subsequent embolization. However, no Meta analysis or large studies have been conducted to state with certainty the hypothesis of "Long tunnel PFO anatomy and its association with cryptogenic strokes".

It is very important to remember when evaluating a patient for the presence of a PFO, that a PFO is present in approximately $25 \%$ of the general healthy population.

A systematic review and meta-analysis of observational studies showed the annual rate of strokes after PFO-closure is approximately $0.3-0.8 \%$, lower than the $1.98-5.0 \%$ in the medical group [3,7]. This translates into an $84 \%$ reduction in the rate of recurrent neurological events when compared to medical management alone.

A prospective study with long term follow-up showed that the presence of a substantial residual shunt after TC-PFO closure was an important predictor of recurrent neurological events with a relative risk of 4.2 [8]. Therefore, the use of a second device for secondary prevention of recurrent neurological events has been an important clinical question. In a retrospective study by Diaz et al., 424 patients with at least a $5 \%$ substantial residual shunt found that the placement of a second device was safe and effective in treating the residual shunt. Moreover, there were no neurological events at a mean follow-up of 3 years. However, the clinical significance of treating residual shunts with a second device would be at least difficult to prove, since the event rate is low even with untreated PFOs [9].

The decision to conduct a device closure and to prevent the occurrence of cryptogenic strokes is still in nascent stage without any firm guidelines coming up. The individual cardiologist has the discretion to decide device closure particularly in those PFO with stroke prone anatomy, particularly lung tunnel type PFO length > $16 \mathrm{~mm}$. However there is a problem of residual shunt after the first device has been in place in PFO to prevent the incidence of strokes, in which the cardiologist sometimes opt for a second device to close the residual shunt and minimize cryptogenic strokes.

\section{References}

1. Cohnheim J. Untersuchungen uber die embolischen processe. Berlin: August Hirschwald. 1872.

2. Homma S, Sacco RL. Patent foramen ovale and stroke. Circulation. 2005 112: 1063-1072.

3. Lechat P, Mas JL, Lascault G, Loron PH, Theard M, Klimczac M, Drobinski G, Thomas D, Grosgogeat $Y$. Prevalence of patent foramen ovale in patients with stroke. N Engl J Med. 1988; 318: 1148-1152.

4. Webster MWI, Smith HJ, Sharpe DN, Chancellor AM, Swift DL, Bass NM Glasgow GL. Patent foramen ovale in young stroke patients. Lancet. 1988; 332: 11-12.

5. Schuchlenz HW, Saurer G, Weihs W, Rehak P. Persisting eustachian valve in adults: relation to patent foramen ovale and cerebrovascular events. J Am Soc Echocardiogr. 2004; 17: 231-233.

6. Stone DA, Godard J, Corretti MC, Kittner SJ, Sample C, Price TR, Plotnick GD. Patent foramen ovale: association between the degree of shunt by contrast transesophageal echocardiography and the risk of future ischemic neurologic events. Am Heart J. 1996; 131: 158-161. 
7. Agarwal S, Bajaj NS, Kumbhani DJ, Tuzcu EM, Kapadia SR. Meta-analysis of transcatheter closure versus medical therapy for patent foramen ovale in prevention of recurrent neurological events after presumed paradoxical embolism. J Am Coll Cardiol Intv. 2012; 5: 777-789.

8. Windecker S, Wahl A, Chatterjee T, Garachemani A, Eberli FR, Seiler C Meier B. Percutaneous closure of patent foramen ovale in patients with paradoxical embolism: long-term risk of recurrent thromboembolic events. Circulation. 2000; 101: 893-898.
9. Diaz T, Cubeddu RJ, Rengifo-Moreno PA, Cruz-Gonzalez I, Solis-Martin J, Buonanno FS, Inglessis I, Palacios IF. Management of residual shunts after initial percutaneous patent foramen ovale closure: a single center experience with immediate and long-term follow-up. Catheter Cardiovasc Interv. 2010; 76: $145-150$
Austin J Neurol Disord Epilepsy - Volume 4 Issue 1 - 2017 ISSN: 2472-3711 | www.austinpublishinggroup.com Kar. (C) All rights are reserved
Citation: Kar SK. Patent Foramen Ovale and Cryptogenic Strokes: Is Device Closure Necessary?. Austin J Neurol Disord Epilepsy. 2017; 4(1): 1030. 